\title{
PREVALENCE OF LOWER CROSSED SYNDROME AMONG GIZA SCHOOLCHILDREN.
}

Moemen H. Taiaa ${ }^{1}$; Yasser M. Aneis ${ }^{2}$ and Hanaa K. Atta $^{3}$

1 Researcher of physical therapy for Basic Science Department, Cairo University.

2 Professor Doctor of Physical Therapy for Basic Science Department, Faculty of physical therapy. Cairo University

3 Lecturer of Physical Therapy for Basic Science Department, Faculty of physical therapy, Cairo University

${ }^{1}$ E-mail- Moementaiaa@gmail.com

Key Words: Lower crossed syndrome, Children ongoing School, muscular imbalance.

\section{ABSTRACT :}

Background : Lower crossed syndrome (LCS) is a musculoskeletal imbalance characterized by specific patterns of muscle weakness (Abdominals and Gluteus Maximus) and tightness (iliopsoas and spinal extensors) that crosses between the dorsal and the ventral sides of the body. This postural imbalance among schoolchildren can lead to Low back pain in future. Purpose of this study is

to investigate the prevalence of lower crossed syndrome in Giza schoolchildren in male and female subjects between the age group of 9 to 12 years. Methods : A total 232 student between age group 9 to 12 years were taken with parents consents. Each student underwent for assessment of strength of abdominal muscles and gluteal muscles with the use of Manual Muscle Test and measurement of tightness of hip flexor muscles with the use of Thomas test, and measurement of tightness of lower back extensors muscles with the use of Schober test .

Results : $12.1 \%$ of the total population have lower crossed syndrome i.e 28 subjects out of 232 total subjects have lower crossed syndrome. Conclusion: Out of the total subjects $12.1 \%$ of subjects were found to be prevalent for lower crossed syndrome.

\section{INTRODUCTION}

Lower Crossed Syndrome (LCS) is a "S" shaped lower back posture characterized by tension in the hip flexors and lower back muscles, as well as weakening in the abdominal and gluteus maximus muscles. It is also known as distal or pelvic crossed syndrome. On the dorsal side of LCS, the thoraco-lumbar extensors are tight and there are tightness also in the iliopsoas and rectus on the other side. While there are weakness in the deep abdominal muscles crosses ventrally with gluteus maximus weakness. Joint dysfunction occurs as a result of this pattern of imbalance, particularly at the 
L4-L5 and L5-S1 segments, the Sacroiliac joint, and the hip joint (Shriya et al.,2017) .

In LCS there are specific postural changes which include increased lumbar lordosis, anterior pelvic tilt, lateral lumbar shift, lateral leg rotation and knee hyperextension. The imbalance is predominantly in the pelvic muscles when the lordosis is deep and short, and the imbalance is predominate in the trunk muscles when the lordosis is shallow and extends into the thoracic area ( Parashar et al .,2014 ).

Joint dysfunction (ligamentous strain and increased pressure particularly at the L4-L5 and L5-S1 segments, the hip joint and the SI joint), specific postural changes (such as increased lumbar lordosis ,anterior pelvic tilt, external rotation of hip, lateral lumbar shift, and knee hyperextension) and joint pain (lower back, hip and knee) results from muscle imbalance . Changes in posture may occur in other parts of the body, such as: increased thoracic kyphosis and increased cervical lordosis (Chaitow et al.,2002 ).

Janda defines muscle imbalance as impairment in the interaction between muscles that are prone to tightness or shortness and those that are prone to inhibition. Our bodies have two types of muscles: phasic muscles like the abdominals and hip extensors, and postural muscles like quadrates lumborum , back rotators ,erector spinae, and the iliopsoas. He noted that both static and postural muscles have a tendency to tighten. (Shriya et al.,2017) .

In various movements, these muscles have a tendency to develop weakness because they are more activated than the muscles which are predominantly dynamic and phasic in function. ( Parashar et al .,2014 )

Janda found that static posture for long time, such as sitting on the desk for many hours, which lead the hip flexors to be shortened or tight. As a result, the brain will begin to shut down or inhibit the gluteus muscles on the opposite side. Because of the forward pelvic tilt and hip flexion contracture, as well as the overuse of the hip flexors to compensate for the weak abdominals, the hip flexors are overworked, this imbalance pattern leads to increasing lumbar lordosis (Dhanani et al.,2014).

Because of the presence of an inhibited antagonistic gluteus maximus, tightness of the psoas would result in a poor quality of hip extension because the contralateral lumbar erector spinae and ipsilateral hamstrings would have to become overactive and eventually tight to perform the required hip extension instead of the gluteus maximus. (Dhanani et al.,2014).

Low back pain is a universal problem and one of the threatening combinations of biomechanical muscle imbalance is lower crossed syndrome, due to over stress it places on the structures in the area of lower back. People with postural imbalance complain from lower back pain and if it is left unchecked, this postural imbalance can generate a chronic low back 
pain that becomes more difficult to correct in later stages. (Shriya et al.,2017) .

According to a study, over a period of 5 years the annual incidence of low back pain in children of age between 11 to 15 gets increasing from $11.8 \%$ to $21.5 \%$. The lifetime prevalence of low back pain increased from $11.6 \%$ to $50.4 \%$ between the age from 11 to 15 years. ( Shrikrushna et al.,2019) .

According to Birger, $85 \%$ of low back pain is caused by muscle imbalance, which is most usually caused by long-term postural defects known as lower crossed syndrome.

Schoolchildren with neck or back pain had more severe functional disability, as measured by a subjective functional disability index. Because of pain, the former group had more difficulties sleeping, sitting during lessons, walking, physical activity, and hobbies.(Mikkelsson et al., 1997).

There are lack of literature evidence, which can show the prevalence of lower crossed syndrome in Schoolchildren (males and females). As a result, the goal of this study was to identify the population at risk of developing lower crossed syndrome, which can lead to low back pain (LBP) in the long run, and to identify a cost-effective musculoskeletal corrective measure that can be implemented at an early stage to reduce the risk of LBP.

Therefore, the present study intended to find out the prevalence of lower crossed syndrome in Schoolchildren within the age group of 9 to 12 years.

\section{MATERIALS AND METHODS}

Design of study: Cross sectional study.

The current study was conducted at 4 schools in Giza government , in the period from March 2019 to November 2020, to evaluated the prevalence of lower crossed syndrome in schoolchildren . After getting ethical clearance from the institutional ethics committee, the consent forms were given to all the parents of children of age between 9 to 12 years. Consents of the parents and assents of 232 children were obtained.

The students participated in the current study after approval of Ethical Committee of the faculty of physical therapy, Cairo University with number (P.T.REC/012/002562), and all subjects provided written inform consent by their parents .

\section{Participants :}

Inclusion criteria :

232 of Both boys and girls willing to participate in the study between the age group of 9 to 12 years. Informed consent form (which also includes permission to use their data and photograph for presentation and publication purpose) written in their preferred language (English/ Arabic) was obtained from parents of the children who agreed to participate. 


\section{Exclusion Criteria :}

The schoolchildren with history of back or lower limb surgery, trauma to back or lower extremity, low back pain since six months, rheumatoid arthritis, spinal deformity, spasm of paraspinal muscle, any neurological disease, and uncooperative schoolchildren were excluded.

All the schoolchildren performed warm up exercises (under therapist's supervision ) 5 repetition of back \& hip flexor stretches before the evaluation of muscle length and strength .

\section{Outcome Measures :}

- The strength of glutues maximus and abdominal muscles are evaluated by Manual Muscle Test Grading.

-The flexibility of the lower back muscles are evaluated by Schober Test, and the flexibility of hip flexors are evaluated by Modified Thomas Test.

\section{Instruments and Scales of assessment :}

1-Goniometer: A goniometer is a device that measures the range of motion at a joint. There are several types of goniometers; the most common is the universal standard goniometer, which is composed of plastic or metal. It comprises of a fulcrum, a stationary arm, and a moveable arm.. Manual goniometers yielded good test-retest reliability and validity (Nussbaumer et al,2010)

2-Tape measurement: A tape measure is a measuring device made of metal, plastic, or fabric with numbers printed on it.

3- The Modified Thomas Test (MTT) : is used to measure the tightness of hip flexor, a specific observational clinical test for posture, postural adaptation, and lower extremity kinematics that is often employed. It indirectly provides information about hip and knee musculature flexibility, particularly the $\mathrm{m}$. iliopsoas, $\mathrm{m}$. rectus femoris, tensor fasciae latae, and sartorius. ( Dalibor et al., 2018 ) . Modified Thomas test were reliable to evaluate hip flexor tightness with Intra-class correlation coefficient $=(0.98)$. ( Kim et al., 2015$)$.

4- Modified-Schober Test : used to measure length of spinal extensor muscles by non elastic measuring tape, this test is classically used to determine if there is a decrease in lumbar spine range of motion (flexion) (Rezvani et al., 2012 ) . The validity against radiographs was. strong $(\mathrm{r}=0.90)$, the reliability was found to be excellent $(\mathrm{r}=0.96)$. ( Tousignant 2005 ).

5- Manual muscle testing Grading : Manual Muscle Test was used to assess the strength of the abdominal muscle and bilateral Gluteus maximus muscle. The use of MMT for patients with musculoskeletal dysfunction has been shown to be reliable and valid. (Cuthbert SC et al.,2007) 


\section{Assessment : \\ Measurement of iliopsoas muscle length ( Norkin et al ,2004 ) :-}

The students were advised to lie supine on the bench with half of their thigh protruding, and the therapist standing near the exam table. The lumbar spine was examined for signs of severe lordosis. To flatten down the lumbar spine and stabilize the pelvis, the volunteers were instructed and demonstrated to pull (flex) and hold the non-tested hip in a flexed posture, bringing the knee close to the chest. With a universal goniometer, the examiner measured the length of the opposite side iliopsoas by keeping the fulcrum above the greater trochanter, the movable arm parallel to the lateral border of the femoral shaft, and the stationary arm parallel to the tested bench. Both sides were subjected to the test. If the hip flexion angle was more than 15 degrees, the iliopsoas was considered tight.

\section{Measurement of strength of abdominal muscle ( Magee D, 2002 ) :-}

The children were placed in a supine position with both hip and knee flexed and hands clasped behind their heads (for Grade-V), arms crossed over the chest (for Grade-IV), and arms outstretched in full extension above the plane of body (for Grade-V) (For Grade-III). During the test, the therapist stood at the side of the table at the level of the child chest to ensure scapular clearance from the table. After that, the children were told to flex their trunks to their entire range of motion. The trunk was emphasised curling up till the scapula cleared the table. "Tuck your chin and lift your head, shoulders, and arms off the table, as if you were doing a sit up," was the instruction.

\section{Measurement of length of spinal extensors muscle (Tousignant et al.,} 2005):

This was assessed in standing position, the child is standing with his back towards the examiner, the intersection between the venus of dimples on the lower back was marked with a marker as a reference line, $10 \mathrm{~cm}$ above and $5 \mathrm{~cm}$ below the therapist draw from the reference line. The child was then asked to bend forward, and the examiner measured the increase in distance with a measuring tape. The outcome measures are the differences between these points.

\section{Measurement of gluteus Maximus strength ( Kendall et al.,1993 ) : -}

The child is asked to lie prone with one knee flexed to 90 degrees. On the tested side, the therapist was standing at the level of the pelvis. The therapist used one hand to apply downward pressure and the other hand at the low back, stabilizing the pelvis. The child was asked to extend his hip while keeping his knees flexed at 90 degree .The therapist apply resistance 
(minimal resistance for Grade 4 and maximum for Grade 5 ) at the lower part on the posterior thigh in the direction of hip flexion so that the child could reach the full range of hip extension. According to MRC grading. The strength of gluteus maximus was graded.

\section{Data analysis and statistical design}

Data were expressed as mean \pm SD. Descriptive statistics was used to determine the frequency of lower crossed syndrome, frequency of hip flexor tightness, abdominal and gluteus Maximus weakness in male and female subjects. Chi-square test was used to find out the homogeneity of proportion of males and females having tight hip flexor, weak abdominal and gluteus Maximus. Statistical package for the social sciences computer program (version 20 for Windows; SPSS Inc., Chicago, Illinois, USA) was used for data analysis. $P$ less than or equal to 0.05 was considered significant.

\section{RESULTS}

This study was conducted to identify schoolchildren at risk of developing lower crossed syndrome at an early stage.

\section{General characteristics:}

The mean $\pm \mathrm{SD}$ of age, of the studied group were $10.59 \pm 1.06$ years (table 1). The studied group was consisted of 232 children 138 males (59.5\%) and 94 females (40.5) Figure(1).

Table (1): The children age of this study.

\begin{tabular}{|l|l|l|l|l|l|}
\hline Items & $\mathbf{N}$ & Minimum & Maximum & Mean & SD \\
\hline Age (years) & 232 & 9 & 12 & 10.59 & 1.06 \\
\hline
\end{tabular}

$\mathrm{N}$ : number, SD: standard deviation

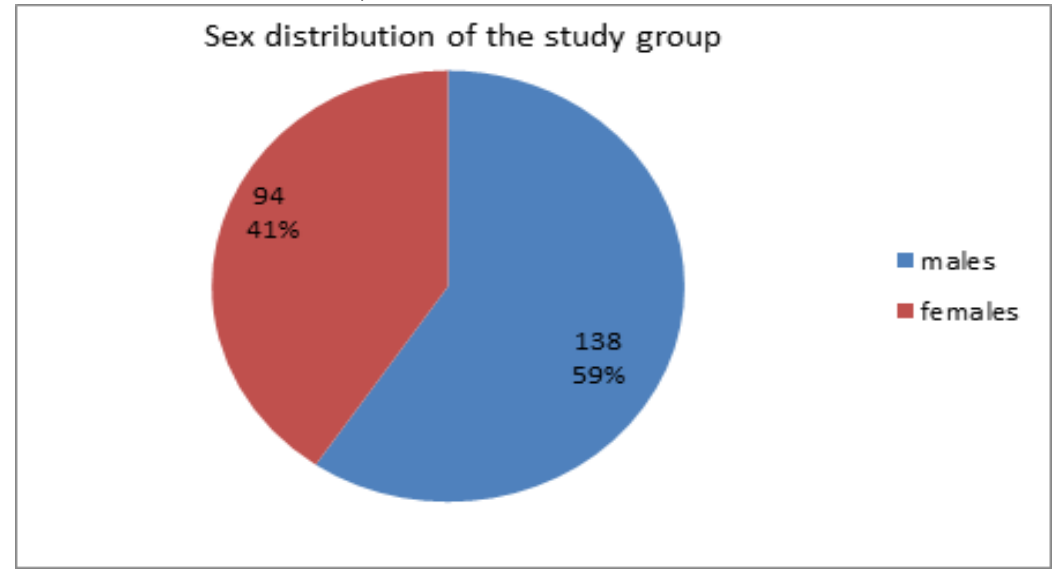

Figure (1): Sex distribution of the study group. 


\section{Normality test:}

Data were screened for normality assumption, homogeneity of variance, and presence of extreme scores. Shapiro-Wilk test for normality showed that all measured variables (hip flexors flexibility by Thomas test, spinal flexibility, abdominal and gluteal muscle strength) were not normally distributed, so Wilcoxon test was for within subjects' comparison. Statistical analysis was conducted using SPSS for Windows, version 20 (SPSS, Inc., Chicago, IL). Alpha level set at 0.05 .

\section{The Prevalence of hip flexion flexibility among children:}

\section{Right hip flexor flexibility:}

- $\quad$ For right hip flexors there were 211 children (90.9\%) with normal hip flexors flexibility (less than 15 degrees hip flexion) and 21 children $(9.1 \%)$ had tight hip flexor (more than 15 degrees hip flexion) (table 2).

Comparison between both sex revealed that, there was no significant difference between both sex $(\mathrm{p}=0.813)$, there were 86 females (91.4\%) and 125 males (90.5\%) with normal hip flexors flexibility. While 8 females $(8.6 \%)$ and 13 males $(9.5 \%)$ had tight hip flexor.

\section{Left hip flexor flexibility:}

- $\quad$ For left hip flexors there were 214 children (92.2\%) with normal

hip flexors flexibility (less than 15 degrees hip flexion) and 18

(7.8\%) children had tight hip flexor (more than 15 degrees hip flexion) (table 2).

Comparison between both sex revealed that, there was no significant difference between both sex $(\mathrm{p}=0.884)$, there were 87 females $(92.5 \%)$ and 127 males $(92 \%)$ with normal hip flexors flexibility. While 7 females (7.5\%) and 11 males (8\%) had tight hip flexor.

Table (2): Percentage of right and left hip flexion flexibility

\begin{tabular}{|c|c|c|c|c|c|}
\hline & & Total 232 & $\begin{array}{l}\text { Female } \\
(n=94)\end{array}$ & Male (138) & p-value \\
\hline \multirow[t]{2}{*}{$\begin{array}{l}\text { Hip flexion } \\
\text { (right) }\end{array}$} & $\begin{array}{l}\text { Normal } \\
\text { (less than 15) }\end{array}$ & $\begin{array}{l}211 \\
(90.9 \%)\end{array}$ & $86(91.4 \%)$ & $\begin{array}{l}125 \\
(90.5 \%)\end{array}$ & \multirow[t]{2}{*}{0.813} \\
\hline & $\begin{array}{l}\text { Tight } \\
\text { (more than 15) }\end{array}$ & $21(9.1 \%)$ & $8(8.6 \%)$ & $13(9.5 \%)$ & \\
\hline \multirow[t]{2}{*}{$\underset{\text { (left) }}{\text { Hip flexion }}$} & $\begin{array}{l}\text { Normal } \\
\text { (less than 15) }\end{array}$ & $\begin{array}{l}214 \\
(92.2 \%)\end{array}$ & $87(92.5 \%)$ & $127(92 \%)$ & \multirow[t]{2}{*}{0.884} \\
\hline & Tight (more than 15) & $18(7.8 \%)$ & $7(7.5 \%)$ & $11(8 \%)$ & \\
\hline
\end{tabular}




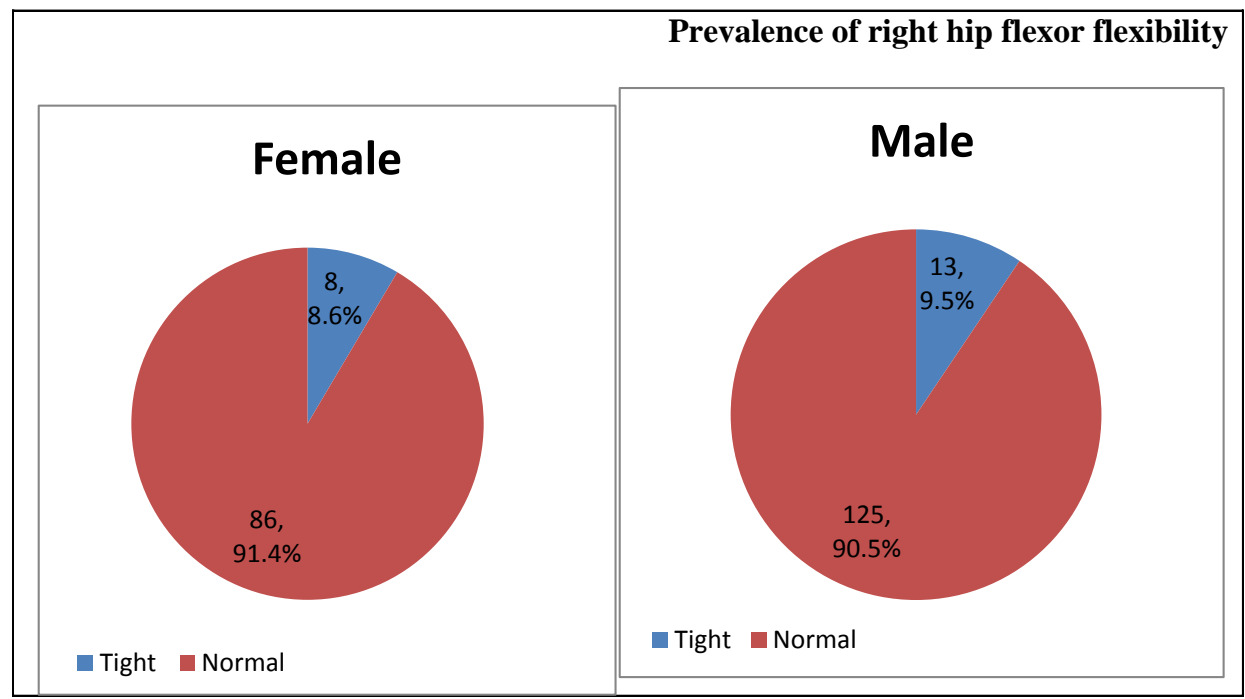

Figure (2 ): Prevalence of right hip flexor flexibility

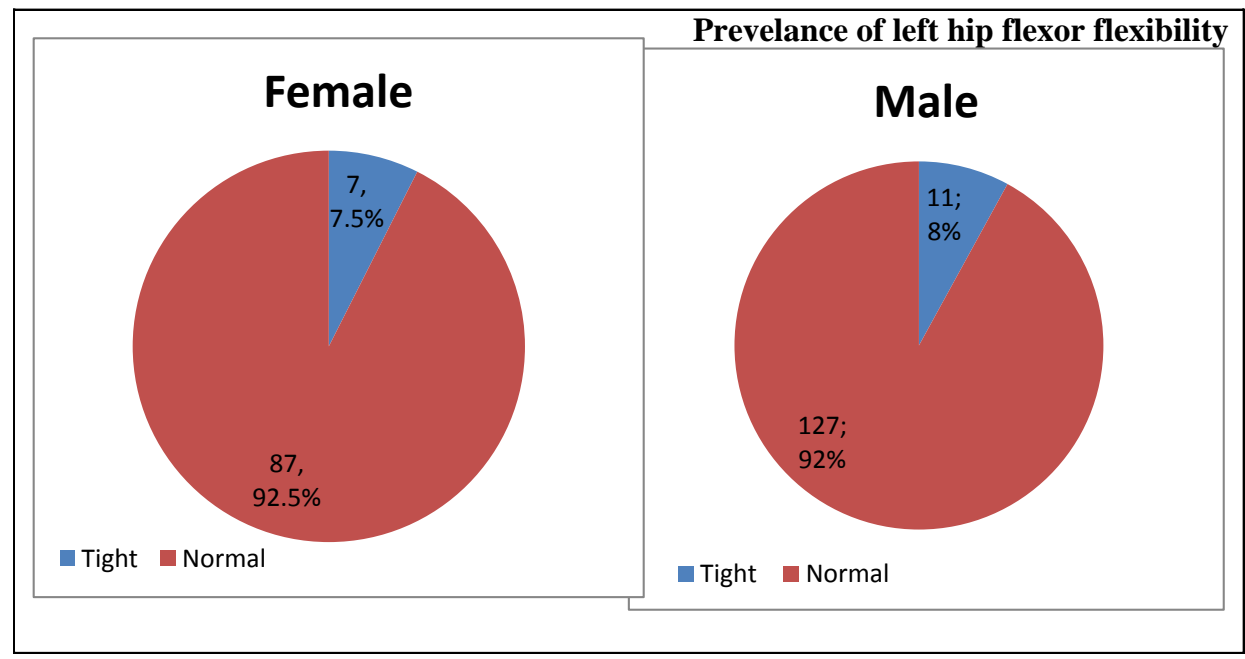

Figure (3): Prevalence of left hip flexor flexibility The Prevalence of Schöber test of lumbar flexor flexibility among children:

- For Schöber test: there were 116 children (50\%) with normal lumbar flexors flexibility (more than $20 \mathrm{~cm}$ ) and 116 children $(50 \%)$ had tight lumbar flexor (less than $20 \mathrm{~cm}$ ) (table 3). 
- Comparison between both sex revealed that, there was no significant difference between both sex $(\mathrm{p}=0.422)$, there were 44 females $(46.8 \%)$ and 72 males $(52.2 \%)$ with normal lumbar flexors flexibility. While 50 females $(53.2 \%)$ and 66 males $(47.8 \%)$ had tight lumbar flexor.

Table (3): Percentage of lumbar flexor flexibility

\begin{tabular}{|l|l|l|l|l|}
\hline Schöber test & Total 232 & Female $(\mathrm{n}=94)$ & Male (138) & p-value \\
\hline $\begin{array}{l}\text { Normal } \\
(\text { more than } 20 \mathrm{~cm})\end{array}$ & $116(50 \%)$ & $44(46.8 \%)$ & $\mathbf{7 2}(52.2 \%)$ & 0.422 \\
\cline { 1 - 1 } $\begin{array}{l}\text { Tight } \\
\text { (less than } 20 \mathrm{~cm})\end{array}$ & $116(50 \%)$ & $\mathbf{5 0}(53.2 \%)$ & $66(47.8 \%)$ & \\
\hline
\end{tabular}

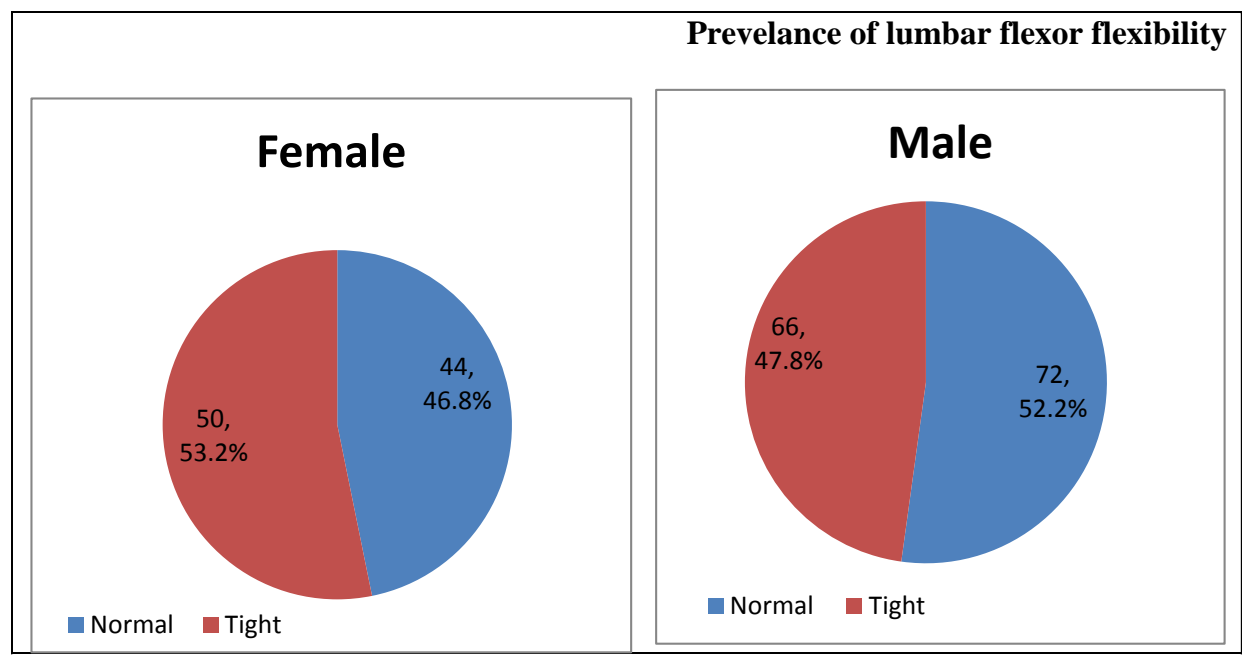

Figure (4 ): Prevalence of lumbar flexor flexibility

The Prevalence of muscle strength among children:

For Abdominal muscle there were $24(10.3 \%)$ had weak abdominal muscle, 208 (89.7\%) had normal abdominal muscle (table 4). There were $24(10.3 \%), 48(20.7 \%), 100(43.1 \%)$ and $60(25.9 \%)$, had grades of manual muscle test of abdominal muscle of 2, 3, 4 and 5 respectively (table 5).

Comparison between both sex revealed that, there was no significant difference between both sex $(\mathrm{p}=0.358)$, there were 10 females $(10.6 \%)$ and 14 males $(10.2 \%)$ had grade 2 MMT. There were 19 females (20.2\%) and 29 males (21\%) had grade 3 MMT, there were 46 females (49\%) and 54 males $(39.1 \%)$ had grade 4 MMT, there were 19 females (20.2\%) and 41 males (29.7\%) had grade 5 MMT 
Table (4): frequency distribution of muscle strength

\begin{tabular}{|c|c|c|c|c|}
\hline Abdominal muscle & Female (94) & Male (138) & Total (232) & p-value \\
\hline Weak & $10(10.6 \%)$ & $14(10.1 \%)$ & $24(10.3 \%)$ & \multirow[t]{2}{*}{0.904} \\
\hline Normal & $84(89.4 \%)$ & $124(89.9 \%)$ & $208(89.7 \%)$ & \\
\hline $\begin{array}{l}\text { Right gluteus muscle } \\
\text { Weak }\end{array}$ & $6(6.4 \%)$ & $8(5.8 \%)$ & $14(6.1 \%)$ & \multirow[t]{2}{*}{0.854} \\
\hline Normal & $88(93.6 \%)$ & $130(94.2 \%)$ & 218 (93.9) & \\
\hline $\begin{array}{l}\text { left gluteus muscle } \\
\text { Weak }\end{array}$ & $7(7.4 \%)$ & $12(8.7 \%)$ & $19(8.2 \%)$ & \multirow[t]{2}{*}{0.733} \\
\hline Normal & $87(92.6 \%)$ & $126(91.3 \%)$ & $213(91.8 \%)$ & \\
\hline
\end{tabular}

Table (5): Comparison of frequency distribution of muscle strength

\begin{tabular}{|c|c|c|c|c|c|c|}
\hline & & \multicolumn{4}{|c|}{ MMT grade } & \multirow[t]{2}{*}{ p-value } \\
\hline & & 2 & 3 & 4 & 5 & \\
\hline \multirow{3}{*}{$\begin{array}{l}\text { Abdominal } \\
\text { muscle }\end{array}$} & Total $(n=232)$ & $24(10.4 \%)$ & $48(20.7 \%)$ & $100(43.1 \%)$ & $60(25.9 \%)$ & \multirow[t]{3}{*}{0.358} \\
\hline & Female (n=94) & $10(10.6 \%)$ & $19(20.2 \%)$ & $46(49 \%)$ & $19(20.2 \%)$ & \\
\hline & Male $(n=138)$ & $14(10.2 \%)$ & $29(21 \%)$ & $54(39.1 \%)$ & $41(29.7 \%)$ & \\
\hline \multirow{3}{*}{$\begin{array}{l}\text { Right } \\
\text { gluteus } \\
\text { muscle }\end{array}$} & Total $(\mathbf{n}=\mathbf{2 3 2})$ & $14(6.2 \%)$ & $64(27.5 \%)$ & $92(39.6 \%)$ & $62(26.7 \%)$ & \multirow[t]{3}{*}{0.491} \\
\hline & Female $(n=94)$ & $6(6.3 \%)$ & $30(32 \%)$ & $32(34 \%)$ & $26(27.7 \%)$ & \\
\hline & Male $(n=138)$ & $8(5.8 \%)$ & $34(24.7 \%)$ & $60(43.5 \%)$ & $36(26 \%)$ & \\
\hline \multirow{3}{*}{$\begin{array}{l}\text { Left } \\
\text { gluteus } \\
\text { muscle }\end{array}$} & Total $(n=232)$ & $19(8.2 \%)$ & $68(29.3 \%)$ & $90(38.8 \%)$ & $55(23.7 \%)$ & \multirow[t]{3}{*}{0.680} \\
\hline & Female $(n=94)$ & $7(7.4 \%)$ & $28(29.8 \%)$ & $40(42.6 \%)$ & $19(20.2 \%)$ & \\
\hline & Male $(n=138)$ & $12(9 \%)$ & $40(29 \%)$ & $50(36 \%)$ & $36(26 \%)$ & \\
\hline
\end{tabular}

\section{Frequency of abdominal muscle strength}

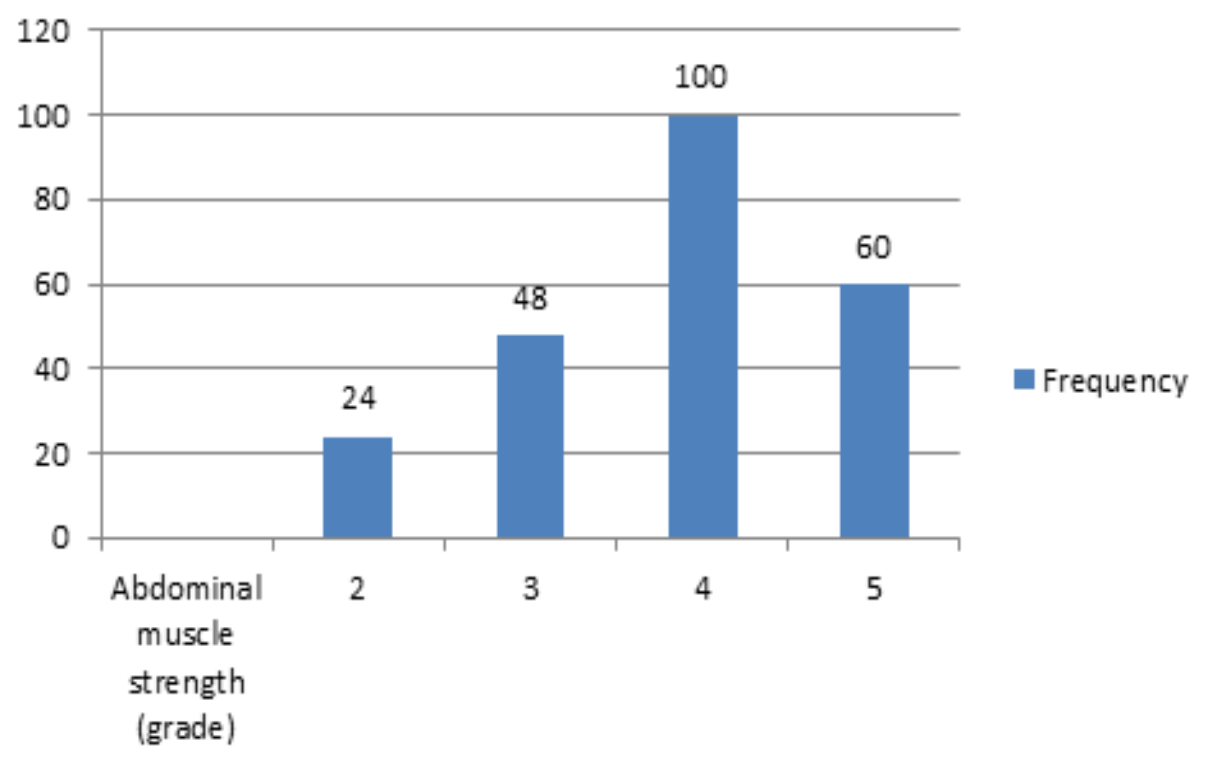

Figure (5): Frequency of abdominal muscle strength among the study group 


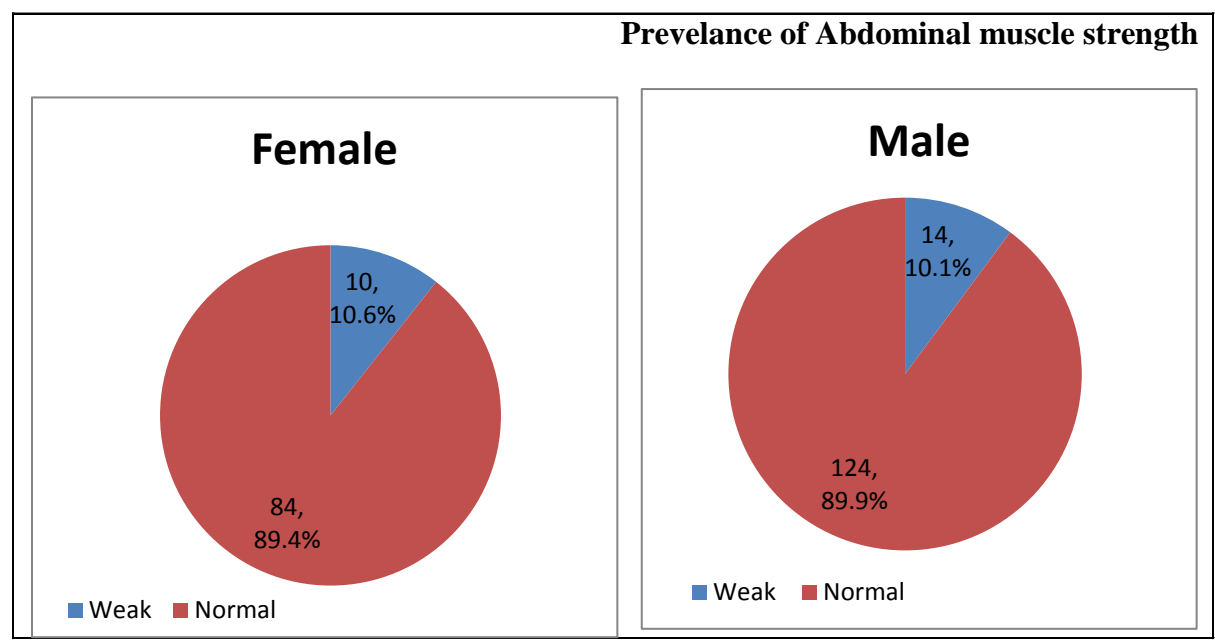

Figure (6): Prevalence of abdominal muscle strength

For right gluteus muscle there were $14(6.1 \%)$ had weak right gluteus muscle and $218(93.9 \%)$ had normal right gluteus muscle (table 4).

There were 14 (6\%), $64(27.6 \%), 92(39.7 \%)$ and $62(26.7 \%)$, had grades of manual muscle test of right gluteus muscle of 2, 3, 4 and 5 respectively (table 5).

Comparison between both sex revealed that, there was no significant difference between both sex $(\mathrm{p}=0.491)$, there were 6 females $(6.3 \%)$ and 8 males $(5.8 \%)$ had grade 2 MMT. There were 30 females $(32 \%)$ and 34 males $(24.7 \%)$ had grade 3 MMT, there were 32 females $(34 \%)$ and 60 males $(43.5 \%)$ had grade 4 MMT, there were 26 females $(27.7 \%)$ and 36 males $(26.8 \%)$ had grade 5 MMT

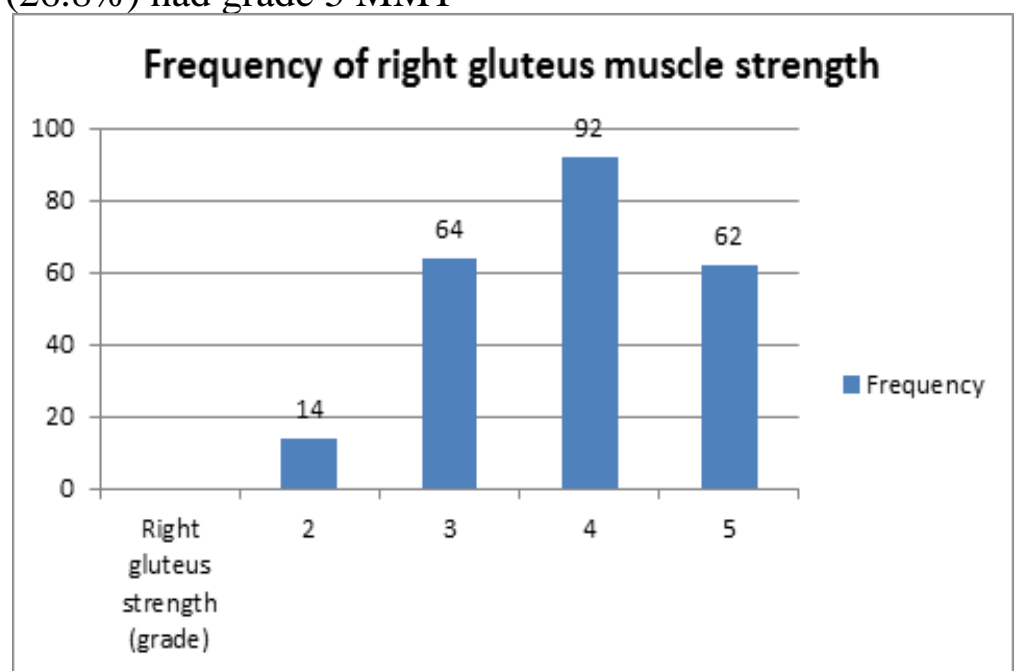

Figure (7): Frequency of right gluteus muscle strength among the study group 


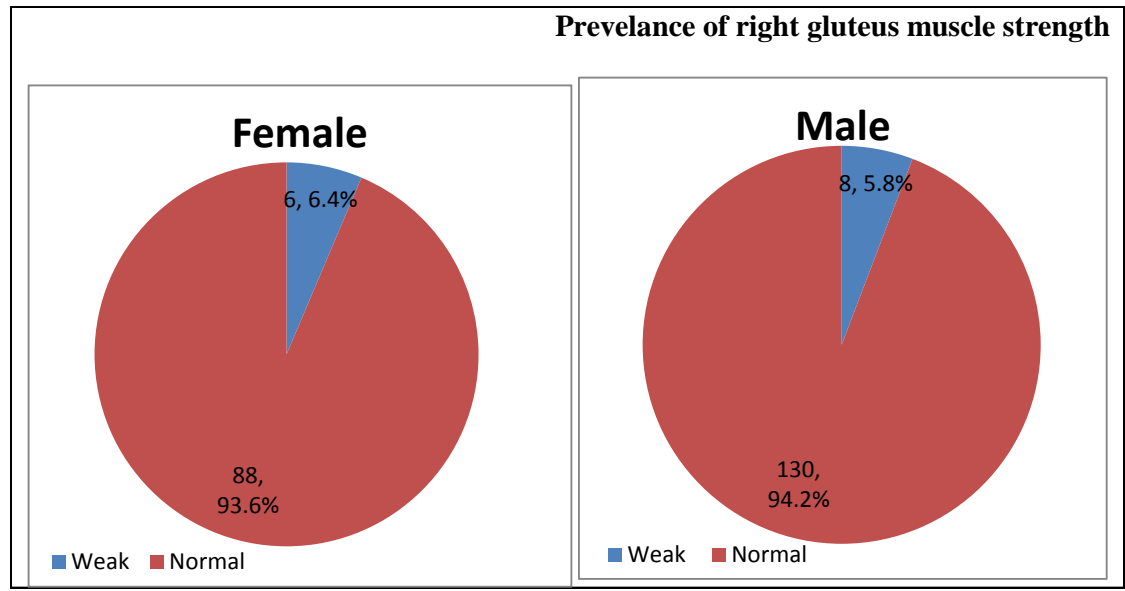

Figure (8): Prevalence of right gluteus muscle strength

For left gluteus muscle there were $19(8.2 \%)$ had weak left gluteus muscle and $213(91.8 \%)$ had normal left gluteus muscle (table 4). There were 19 (8.2\%), 68 (29.3\%), $90(38.8 \%)$ and 55 (23.7\%), had grades of manual muscle test of left gluteus muscle of 2, 3, 4 and 5 respectively (table 5).

Comparison between both sex revealed that, there was no significant difference between both sex $(\mathrm{p}=0.680)$, there were 7 females $(7.4 \%)$ and 12 males $(9 \%)$ had grade 2 MMT. There were 28 females $(29.8 \%)$ and 40 males (29\%) had grade 3 MMT, there were 40 females $(42.6 \%)$ and 50 males $(36 \%)$ had grade 4 MMT, there were 19 females $(20.2 \%)$ and 36 males $(26 \%)$ had grade 5 MMT

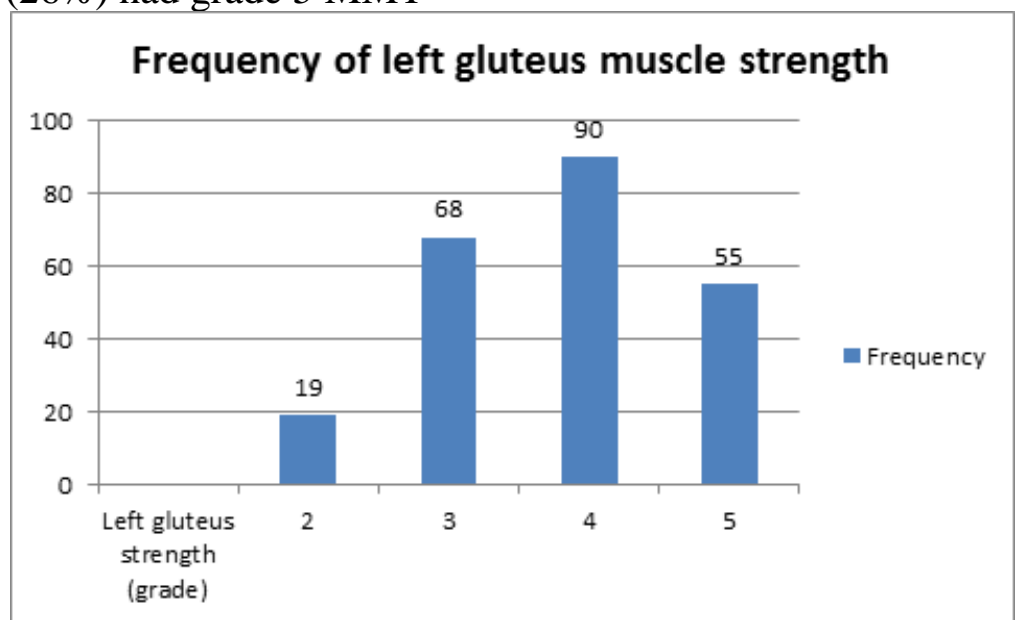

Figure (9): Frequency of left gluteus muscle strength among the study group 


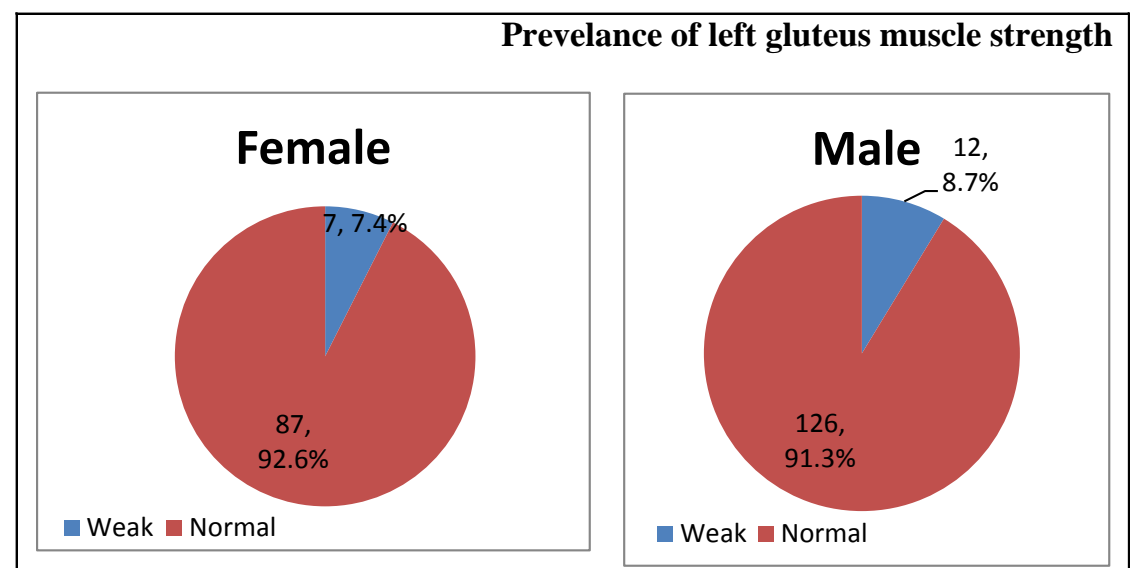

Figure (10): Prevalence of left gluteus muscle strength

\section{Prevalence of lower crossed syndrome}

There were $28(12.1 \%)$ from the children had lower crossed syndrome and there were $204(87.9 \%)$ hadn't lower crossed syndrome (table 6).

Comparison between both sex revealed that, there was no significant difference between both sex $(\mathrm{p}=0.497)$, there were 13 females $(13.8 \%)$ and 15 males $(10.7 \%)$ were affected. There were 81 females $(86.2 \%)$ and 123 males $(89.1 \%)$ were not affected.

Table (6): Prevalence of lower crossed syndrome among males and females

\begin{tabular}{|l|l|l|l|l|}
\hline & Female $(n=94)$ & Male $(n=138)$ & Total $(n=232)$ & p-value \\
\hline Affected & $13(13.8 \%)$ & $15(10.9 \%)$ & $28(12.1 \%)$ & \multirow{2}{*}{0.497} \\
\hline Normal & $\mathbf{8 1}(\mathbf{8 6 . 2 \%})$ & $123(89.1 \%)$ & $204(87.9 \%)$ & \\
\hline
\end{tabular}

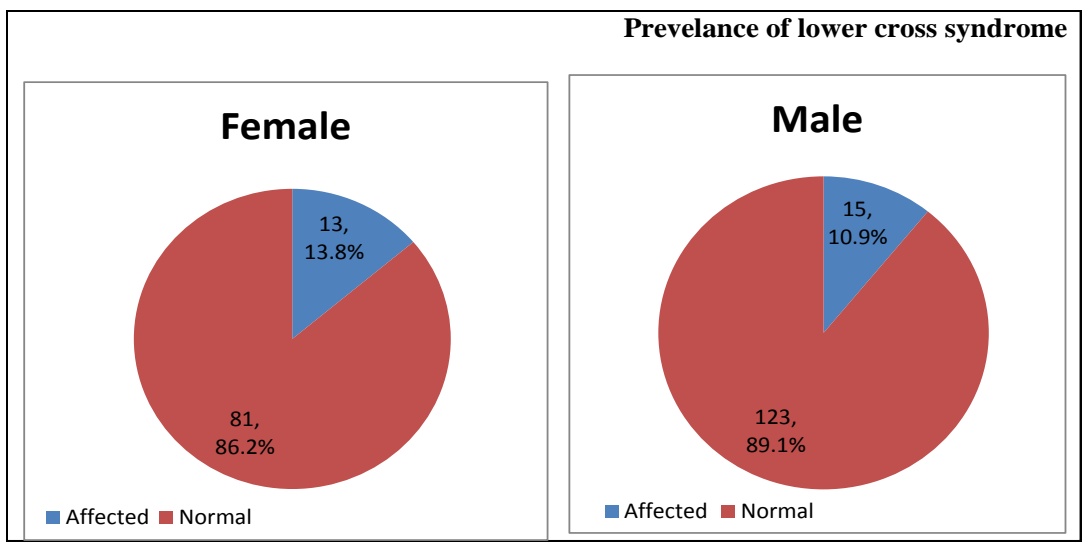

Figure (11): Prevalence of lower cross syndrome 


\section{Power of the study:}

The power of the study was measure by G*Power 3.1 software was, with sample size 232 subjects, 0.05 type I error ( 2 tailed) and effect size of 0.15 ; the power is 0.99 .

\section{DISCUSSION}

One of the most common reasons of low back pain in young individuals is muscle imbalance .Lower crossed syndrome (LCS) is a muscle imbalance characterized by weakness of the gluteus maximus muscle and abdominal muscles, as well as tightness of hip flexors, lower back muscles, ,all this changes alter the biomechanical force distribution in the lower back region, leading to chronic low back pain.(Shriya et al.,2017)

The time children spend in a seated position is average 7-8 hours a day, which consists of 6-7 hours in school, 1-2 hours in tuitions, 1 hour in front of television. This time reaches its peak in between 11 to 13 years. (Justyna et al., 2015 )

There are lack of literature which can state the prevalence of LCS among children, so this study was focused on prevalence of lower crossed syndrome in schoolchildren of age 9 to 12 years.

After getting ethical clearance from the institutional ethics committee, the consent forms were given to all the parents of children of age between 9 to 12 years. Consents of the parents and assents of 232 children were obtained. After getting the consent, manual muscle testing for checking the weakness of abdominal and gluteal muscle, and Thomas test was performed for checking the hip flexor tightness and Schober Test was performed to measure lower back flexibility.

This study was applied in 5 schools in Giza Government Schools, In this study 232 student were enrolled, According to the data analysis of the current study we found that there were 211 children $(90.9 \%)$ with normal RT hip flexors flexibility and 21 children $(9.1 \%)$ had tight RT hip flexor, there were 214 children $(92.2 \%)$ with normal LT hip flexors flexibility and 18 (7.8\%) children had tight LT hip flexor , there were 87 females $(92.5 \%)$ and 127 males (92\%) with normal hip flexors flexibility. While 7 females (7.5\%) and 11 males (8\%) had tight hip flexor.

There were 116 children $(50 \%)$ with normal lumbar flexors flexibility and 116 children (50\%) had tight lumbar flexor. 44 females $(46.8 \%)$ and 72 males $(52.2 \%)$ with normal lumbar flexors flexibility. While 50 females $(53.2 \%)$ and 66 males (47.8\%) had tight lumbar flexor.

Regarding to the strength of gluteus and abdominal muscle, there were $14(6.1 \%)$ had weak right gluteus muscle and $218(93.9 \%)$ had normal right gluteus muscle , 6 females $(6.3 \%)$ and 8 males $(5.8 \%)$ had grade 2 MMT, there were 19 (8.2\%) had weak left gluteus muscle and $213(91.8 \%)$ had normal left gluteus muscle, there were 7 females (7.4\%) and 12 males 
(9\%) had grade 2 MMT, and also we found that there were $24(10.3 \%)$ had weak abdominal muscle, $208(89.7 \%)$ had normal abdominal muscle , 10 females $(10.6 \%)$ and 14 males $(10.2 \%)$ had grade 2 MMT.

Prolonged sitting causes hip flexor tightness which causes anterior pelvic tilt which promotes lumbar lordosis. This causes weakness of gluteal muscles and abdominal muscles. This pattern of muscular weakness give rise to low back pain. (Shrikrushna et al.,2019) .

In the general population, muscle tightness is caused by an increase in tension caused by active or passive mechanisms. Due to spasm or contraction, muscles can become shorter when they are active. A muscle on the other hand, can be passively shortened as a result of postural adaptation or scarring. Tightness, regardless of the cause, restricts range of motion and can lead to muscular imbalance. Soft tissues such as muscles and ligaments are unable to keep up with the rate of bone growth during periods of rapid growth, resulting in muscular imbalances and a decrease in flexibility in the young population. ( Janssen J.et al., 2014 )

Janda found that muscles have a tendency to be either tight or weak in dysfunction. Because of the overload caused by poor posture and ergonomics, they are prone to tightness. Muscles that are prone to tightness are often found to be weak, whereas muscles that are prone to weakness are often found to be tight. According to Janda's LCS model, hip flexors and spinal extensors muscles are prone to tightness due to their tonic character, whereas gluteus maximus and abdominal muscles are prone to muscle weakening due to their phasic nature. (Shriya et al.,2017) .

According to a study, the incidence of low back pain in children of age between 11 to 15 years gets increasing from $11.8 \%$ to $21.5 \%$ over a period of 5 years. (Burton et al ., 1996 )

Furthermore, the present study are in agreement with a pervious study found that prevalence of lower crossed syndrome are more in boys which is $22 \%$ as compared to girls which is $18 \%$ in school going children of age 11 to 15 years. (Shrikrushna et al.,2019), which used to measure the flexibility of hip flexor using Thomas test ,and strength of gluteus maximus and abdominal muscle using Manual muscle test. .

While this study was inconsistent with a study found that prevalence of lower crossed syndrome in females were higher than males at age 21 to 31 year.( (Shriya et al.,2017) and another study stated that there is $85 \%$ of young females have lower cross syndrome at age 16-22 year. (Dhanani et al.,2014). Both of this studies measured 3 outcomes: strength of gluteus maximus , abdominal muscle and flexibility of hip flexors.

According to Mills M et al (2015), restricted hip flexor muscle length is thought to reduce neuronal drive to the hip extensor musculature. Reciprocal inhibition of the gluteus maximus, which occurs as a result of 
over activity of the hip flexor muscle group, has been linked to lower extremity injury.

\section{CONCLUSION :}

The study concludes that there is $12.1 \%$ of school going students of age 9 to 12 years have incidence of lower crossed syndrome, 13 females $(13.8 \%)$ and 15 males $(10.7 \%)$ were affected.

\section{Conflict of interest:-}

There are no conflicts of interest reported by the authors for this study. This article's content and writing are solely the responsibility of the writers.

Funding:-

To complete this project, no funding were received from any organisation or individual.

\section{REFERENCE:}

Burton, A.K. ; R.D. Clarke ; T.D. McClune and K.M. Tillotson (1976). The natural history of low back pain in adolescents. Spine., 21(20):2323-8.

Chaitow, L. and J.W. DeLany (2002). "Clinical application of neuromuscular techniques: the lower body": Churchill livingstone. 2:26-36.

Cuthbert, Scott C. and George J. Goodheart Jr.(2007) "On the reliability and validity of manual muscle testing: a literature review." Chiropractic \& osteopathy ., 15 4. 6 Mar. 2007.

Dalibor Kiseljak, Filip Bolčević ; Daria Ćurko ; Krešimir Pažin ; Filip Ujaković, Igor Gruić and Vladimir Medved (2018) . Acute Effects of Gravitational Stretching in the Position of Modified Thomas Test on Changes in Range of Motion in Hip and Knee Joints., 7(3):180-189 .

Dhanani S.A(2014) "survey on prevalence of lower crossed syndrome in young females." IJPSH.; 1: 2238-2249.10

Janssen, J. ; S.B. Heymsfield ; Z.M. Wang and R. Ross(2014): Skeletal muscle mass and distribution in 468 men and women aged 18-88 years. JAppl Physiol.;116(10):1342

Jones, G.T. and G.JMacfarlane(2005). "Epidemiology of low back pain in children and adolescents ". Arch Dis Child; 90:312-316.

Justyna, Drzal-Grabiec ; Slawomir Snela ; Justyna Rykala ; Justyna Podgorska and R. Maciej (2015): "Effect of the sitting position on the body posture of children aged 11 to 13 years". Work.;51(4):855-862 . 
Kendall, F.P. ; E.K. McCreary and P.G. Provance(1993)."Testing and function. 4th ed." Baltimore: Williams \& Wilkins., Muscles .

Kim, Gyoung-Mo, and Sung-Min Ha. (2015): "Reliability of the modified Thomas test using a lumbo-plevic stabilization." Journal of physical therapy science., 27(2): 447-9.

Magee, D.(2002): "Orthopedic physical assessment. WB Saunders 4th Ed" - pg 478, 483, 631.

Mikkelsson, M., J. J. Salminen and H. Kautiainen (1997). "Nonspecific musculoskeletal pain in preadolescents. Prevalence and 1-year persistence." Pain., 73(1): 29-35.

Mills, M. ; B. Frank ; S. Goto; T. Blackburn ; M. Clark ; A. Aguilar and N. Fava (2015): Effect of restricted hip flexor muscle length on hip extensor muscle activity and lower extremity biomechanics in college aged female soccer players. IJSPT.; 10(7):946.

Norkin, C.C. and D. White(2004) "Measurement of joint motion-a guide to goniometry 3rd. ",Philadelphia, F.A Davis Company J., p.334-336,340 .

Nussbaumer, S. ; M. Leunig ; J.F. Glatthorn and et al.(2010): Validity and test-retest reliability of manual goniometers for measuring passive hip range of motion in femoroacetabular impingement patients.. BMC Musculoskelet Disord., 11: 194.

Parashar, P. ; R. Arunmozhi and C Kapoor (2014) "Prevalence of low back pain due to abdominal weakness in collegiate younge females". Ind J PT., 2 (1):443-460 .

Rezvani, A. ; O. Ergin ; I. Karacan and M. Oncu(2012) Validity and reliability of the metric measurements in the assessment of lumbar spine motion in patients with ankylosing spondylitis. Spine ., 37(19):E1189-96.

Shrikrushna, S.K. and G.Sayali (2019) " Prevalence of Lower Crossed Syndrome in School Going Children of Age 11 To 15 Years ". Ind $J$ Pt and $O T, .13$, No. 2.

Shriya, D. ; B. Sarkar ; R. Sharma ; M. Mondal ; P. Kumar and P. Sahay (2017). "Prevelance of Lower Crossed Syndrome in young adults". Int.J.Adv Res ,5(6):2217-2228 .

Tousignant, M. ; L. Poulin ; S. Marchand ; A. Viau and C. Place (2005) "The Modified-Modified Schober Test for range of motion assessment of lumbar flexion in patients with low back pain" . Disability and rehabilitation. 2005 May 20;27(10):553-9 . 


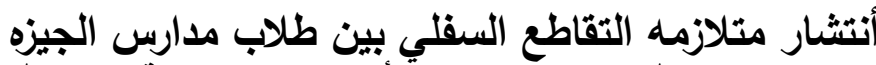

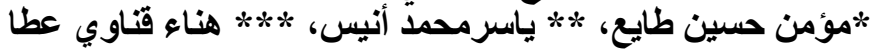

* باحث علاج طبيعى بقسم العلوم الاساسيه .جامعه القاهره

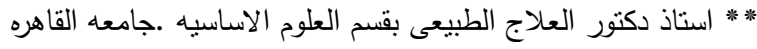

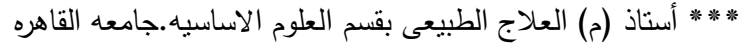

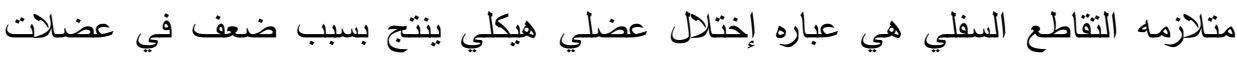

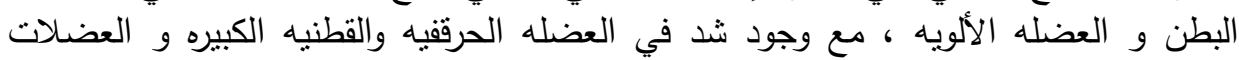
الناصبه للفقار •

الهرف : تحديد مدي انتشار متلازمه التقاطع السفلي بين طلاب مدارس الجيزه الذكور والإناث ، عن طريق إجراءإختبار عضلي يدوي لعضلات البطن و العضله الالويه ، و إختبارات أخري لئ

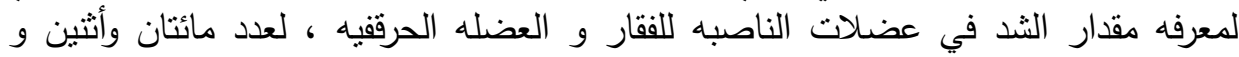

ثلاثون طالب و طالبه من المراحل الإبتدائيه في مدارس محافظه الجيزه ،النتائج : وجود

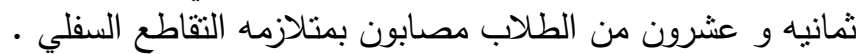

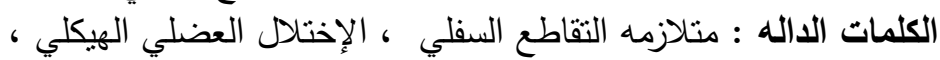

